\title{
"YOUNG AMERICANS": O BLUE-EYED SOUL DE DAVID BOWIE E O PRIVILÉGIO BRANCO
}

\author{
Victor Henrique de Morais Schons ${ }^{1}$
}

David Bowie, nome artístico de David Robert Jones, foi um cantor e compositor nascido em Londres, na Inglaterra, em 1947. Bowie veio a falecer em 2016 e deixou um legado musical de quase cinco décadas em estilos sonoros dos mais variados ${ }^{2}$.

Bowie experienciou uma fase soul, marcada pelo seu nono álbum de estúdio, Young Americans (1975). Dedico-me, aqui, à análise histórica e à resenha deste álbum, bem como de sua compreensão e inserção no gênero concebido como "blue-eyed soul", isto é, a música originalmente da comunidade negra estadunidense (soul ou $R \& B$ - "rhythm and blues") na

${ }^{1}$ Graduando no $3^{\circ}$ ano de História (Licenciatura e Bacharelado) pela Universidade Federal do Paraná. Atualmente, desenvolve pesquisa sob a orientação da $\operatorname{Prof}^{a} \operatorname{Dr}^{a}$ Priscila Piazentini Vieira (UFPR) voltada para os temas: fascismo, ódio, terrorismo de extrema-direita e internet na História Recente. Email para contato: v.henrique.m.s@gmail.com. Endereço para o Currículo Lattes: http://lattes.cnpq.br/150905960629 3258.

${ }^{2}$ Conforme o jornalista Peter Doggett, Bowie teria declarado ser "muito volúvel" (sem datação apud DOGGETT, 2014: 96). Ora, nota-se essa volubilidade no curso das análises de Doggett, percebendo que Bowie explorou estilos musicais dos mais variados, como o rockabilly; um pop quase infantil; o folk rock; o hard rock; e o pop rock; para, em 1972, assumir a sua primeira persona, "Ziggy Stardust": era então um dos maiores nomes do glam rock. Essa evolução de Bowie viu, posteriormente, chegar influências do soul, do $R \& B$ e do funk afro-americanos; e depois mais mil facetas sucessivas do músico que, agora, não são relevantes para a análise. 
voz ou mãos de artistas brancos. A análise das faixas será feita na ordem em que se apresentam no álbum, ignorando a cronologia de gravação. Debruçar-me-ei sobre o disco original lançado em 1975, sem remeter às faixas bônus do CD de 1991. Para fins do escrutínio, as análises aqui feitas partem do exame que o jornalista da música Peter Doggett realizou no livro O homem que vendeu o mundo: David Bowie e os anos 70 (2014), em que versa sobre a trajetória musical do artista de 1969 até 1980.

Young Americans (DOGGETT, 2014: 295-298) é a primeira faixa do álbum. Possui uma letra emocionalmente inspirada, tratando da atração do mítico “jovem americano”. Este é idolatrado, fantasiado, um sonho global. Contudo, nos tempos da gravação da música (1974), a economia nacional era naufragante, e os símbolos de referência perdiam o brilho (vide Escândalo do Watergate $^{3}$ ). Nessa onda, o destino de um jovem americano passa a ser incerto. O sonho acabou, como diz a letra: "Nós vivemos apenas por esses vinte anos/Nós devemos morrer pelos cinquenta restantes?’. Mas a fantasia, diz Doggett (2014: 296), era irresistível; e isso acabou reabastecendo os jovens americanos, que já esqueceram Nixon e "o ontem". Apresenta-se, então, a imagem de um jovem americano cheio de dúvidas, sem saber qual mito seguir. Isso é acompanhado por uma cacofonia que reverbera trechos incompletos já cantados na música. Nesta canção, a voz de Bowie vai ao limite. A estrutura musical, para Doggett, é

3 O escândalo político do Watergate envolveu o então presidente republicano Nixon que, em 1974, após acusações de envolvimento com uma invasão à sede do Partido Democrata, renunciou após a abertura de um processo de impeachment. Acredita-se que a invasão ao núcleo democrata estivesse relacionada com espionagem e sabotagem política. 
agradavelmente leve e os acordes, simples. Ademais, há muito espaço deixado no arranjo; o saxofone concorre com a voz principal; e o coro evidencia-se em "torno e contraponto".

Win, por sua vez, trata do drama emocional de um eu-lírico que tem suas investidas recusadas por uma mulher. O tema lembra a embriaguez, afirma Doggett (2014: 307), já que “os sons têm mais importância que as palavras": nada dito tem tanto sentido e nada aparece bem focado: os instrumentos trinam e reverberam, o saxofone alça voo até tornar-se inaudível e a voz principal oscila entre murmúrio, canto ardente e desespero. O vocal de apoio, aqui, oferece tão somente apoio. Os acordes são suavizados ao longo das estrofes, criando a sensação de algo "não terminado" (DOGGETT, 2014: 307).

A terceira faixa, Fascination, foi baseada na composição original de um dos vocalistas de apoio, Luther Vandross (DOGGETT, 2014: 308). A canção original, Funky Music, com arranjo quase inalterado, tornou-se Fascination nas mãos de Bowie, retocada onde necessário. Tem um clima mais funky, com uma variação de Bowie entre personagens vocais, de murmúrio até um tom mais "manhoso". Segundo Doggett (2014: 308), celebra a "volúpia" e a "força" masculinas. Possíveis inspirações para o título, repetido sem cessar na música, são a "arte oculta" do hipnotismo (do livro de Brennan, Occult Reich, 1974) e a fachada de um clube gay do livro As Cidades da Noite (de Rechy, 1964).

Já a canção Right tem uma estrutura mais "esquelética" (DOGGETT, 2014: 306). O movimento durante os refrões, afirma Doggett (2014: 306), é 
mais leve, acompanhado de uma longa interação entre o vocal principal e os de apoio. Bowie alterna, também aqui, entre interpretações vocais: vai da súplica até os gritos. Nota-se, assim, um esquema meticulosamente planejado, comum ao soul, do call and response.

Somebody Up There Likes Me (DOGGETT, 2014: 303-305) é uma canção que, como afirma o próprio cantor, alerta o Ocidente da iminência de um Hitler (BOWIE, 1974 apud DOGGETT, 2014: 303). Isto é, de um líder autoritário vendido como produto e como ídolo pop em campanha publicitária. O título foi colhido de um filme de 1956 de Paul Newman sobre o campeão de boxe Rocky Graziano, e Doggett (2014) nota que a música explora a confusão da "publicidade, do estrelato e do poder". Expõe-se, com isso, a exuberância de cordas de orquestra; um saxofone pungente e um vocal de Bowie notadamente sedutor (já que a letra da música se trata do engodo); aqui, novamente o vocal oscila entre personagens vocais.

A canção lançada em 1970 pelos Beatles, Across the Universe, recebeu um cover feito por Bowie (DOGGETT, 2014: 311-312). Há, aqui, uma colaboração efetiva com John Lennon, que escreveu a original após uma discussão com a esposa Cynthia, canalizando a frustração em forma de música. Bowie, no clímax deste cover, berra e imita a "voz rasgada" (DOGGETT, 2014: 312) do ex-Beatle, que participou da gravação tocando guitarra.

Can You Hear Me (DOGGETT, 2014: 284-285), em seguida, é uma balada romântica, emocional e elegante dedicada a um(a) amante. Versa 
sobre o tédio dos vários parceiros sexuais disponíveis a Bowie. O título reflete um temor existencial do britânico: de fato existo? ("Can you hear me?" - "Você pode me escutar?"). Foi uma canção, conforme Doggett (2014), composta para a voz da cantora escocesa Lulu. Junta elementos do soul, como um piano em estilo gospel; guitarras com "figuras bem amarradas e concisas" (DOGGETT, 2014: 284); espaçamento no arranjo; e uma relação significativa entre voz principal e vozes de apoio.

Por fim, Fame (DOGGETT, 2014: 312-316), um enorme sucesso como single, atingiu o primeiro lugar na Billboard. A música, conta Doggett (2014), surgiu durante uma sessão improvisada com Lennon, à qual o ex-Beatle fez uma breve contribuição na letra; Carlos Alomar viu aqui retomado o seu arranjo de guitarra originalmente encontrado na música não lançada Footstompin. É, quiçá, um híbrido entre rock e funk. Explora relações complexas entre o piano elétrico, a guitarra e a bateria. A letra, por sua vez, trata-se do estrelato do próprio Bowie e também comenta sobre o empresário Tony Defries ${ }^{4}$. A canção apresenta-se com elementos muitos divergentes entre si, inclusive com a voz esporádica de Lennon e uma série de sons vocais, todos diferentes, gravados por Bowie e manipulados eletronicamente.

Antes de Young Americans, o rockstar britânico já havia flertado com elementos musicais afro-americanos. Segundo Doggett, por influência do seu meio-irmão, Bowie escutava artistas negros desde a adolescência, como

\footnotetext{
${ }^{4}$ Tony Defries foi contratado por Bowie como seu empresário musical desde cerca de 1969 até o início de 1975, quando foi demitido pelo astro pela relação pessoal entre ambos estar comprometida.
} 
John Coltrane, Eric Dolphy e Little Richard (2014: 34-41). Baseado em Doggett (2014), posso mapear uma considerável quantidade de aproximações que o cantor fez com os gêneros $s o u l, R \& B$ ou gospel nas suas composições antes do álbum Young Americans. No total, Doggett elenca 11 músicas nesse sentido na carreira de Bowie ${ }^{5}$, e eu aumento o número para $17^{6}$. Dessas, algumas canções, como I Am a Laser (c. 1973), são pura e simplesmente obras do gênero soul; enquanto que outras, como é o caso de todo o álbum Diamond Dogs (1974), são uma mescla do rock clássico com alguns elementos de origem musical inegavelmente negra. É

${ }^{5}$ Aqui listo músicas que Doggett descreveu como tendo inspiração no $\operatorname{soul}, R \& B$, doo-wop ou gospel, ou contendo elementos musicais destes. Em ordem cronológica: It Ain't Easy (um cover da música de Ron Davies feito em 1972); Five Years (1972); Soul Love (1972); Here Comes The Night (cover de Bert Berns feito em 1973); Everything's Alright (cover de The Mojos feito em 1973); I Am Divine (dado para os Astronettes circa 1973); I Am a Laser (idem); People from Bad Homes (idem); 1984 (1974); Dodo (1974); e Rock 'n' Roll With Me (1974).

${ }^{6}$ Embora Doggett não mencione na análise das seguintes músicas que elas têm inspiração ou elementos dos gêneros pré-mencionados, uma audição atenta delas percebe uma aproximação, e às vezes uma alusão, a outras composições nesses estilos. Em ordem cronológica: Lady Grinning Soul (1973), pelo vocal apaixonado e de alto alcance das notas, além do piano jazzístico; Candidate (versão alternativa), pela predominância sonora do piano jazzístico e pelo ritmo "pegajoso" e funky; Sweet Thing (1974), pelo grande comprometimento emocional do cantor na expressão intérprete da canção, que é lenta, cativante e com uma enorme variante de alcances vocais (da voz principal auxiliada por um coro), acompanhados por um piano e um saxofone tão apaixonados quanto a voz; Candidate (1974), idem, tratando-se de uma continuação à música anterior; Sweet Thing (reprise, de 1974), idem, pelo mesmo motivo; Big Brother (1974), pelo uso de um vocal ascendente que alcança baixas e altas notas, tendo por companhia trompetes e saxofones em ritmo similar ao do blues; e Diamond Dogs (1974), pelo claro uso do coro como call and response, o que é comum no estilo soul. 
por volta do ano de 1974 que o londrino viria a se tornar um expoente blue-eyed soulster (BUCKLEY, 2012: 72).

O blue-eyed soul, contudo, é um gênero musical que reside na controvérsia. Sobre o estilo, que possuía Elvis Presley como vanguarda, a musicóloga Joanna Demers (2006: 31, tradução minha) assim escreveu, assumindo o poeta negro Scott-Heron por referência:

Elvis não era "coisa nova" porque ele pertencia a uma longa tradição de cooptação branca da identidade cultural negra. Para Scott-Heron, Presley e seus sucessores no blue-eyed soul e funk branco provaram que os negros ainda estavam sendo vitimados pela apropriação cultural.

Além da questão de apropriação, a polêmica do blue-eyed soul se estende no passo em que os brancos, ao assumirem os estilos negros, descaracterizavam a essência dessas músicas, que muito tratavam de temas que envolvessem a experiência de vida negra; e ofuscavam artistas afrodescendentes a partir do seu sucesso, já que esse se dava em virtude da sua raça privilegiada. Como membros da raça branca, estavam mais propensos a alcançar o sucesso numa sociedade estruturalmente racista, e assim iam tomando espaços tradicionais negros.

O tema do racismo na indústria musical seria abordado pelo próprio Bowie em uma entrevista ao canal MTV, dedicado à promoção audiovisual de músicos na plataforma televisiva, quase um decênio depois da publicação de Young Americans. O britânico criticou a MTV por ter "tão poucos artistas negros apresentados" (2017: não p., tradução minha). 
"Parece ter um monte de artistas negros fazendo vídeos muito bons que eu estou surpreso que não são usados na MTV" (BOWIE, 2017: não p., tradução minha). Nisso, Bowie endereçava o racismo estrutural observado no mercado: por que não são dadas as mesmas oportunidades aos negros? Por que são ignorados os conteúdos que eles produzem?

Enfim, lembro que a existência do blue-eyed soul não significa que, quando artistas brancos compõem e interpretam estilos musicais negros, estão a fazer algo de racista propositada e pessoalmente. Na verdade, o que há mesmo de racista é o sistema excludente do mercado, e também da sociedade ocidental como um todo, que privilegia o branco. A música pode ser bem feita pelos brancos; mas o sistema torna os afrodescendentes injustamente preteridos e marginalizados no mundo musical. Nisso, vale ressaltar que o Ocidente sofre com um racismo onipresente, sobrevivente de séculos, que lança raízes nas suas instituições.

É digno de nota que Bowie não era racista, mas o era o sistema que preferiu ele e outros artistas brancos. Bowie incentivava músicos negros e tinha amizade com a comunidade afrodescendente americana (DANIEL, 2016 apud SIMON, 2016: não paginado), tendo sido convidado por ela para ter presença em programas como o Soul Train (em 1975) e Video Soul (c. 1981-1996). O DJ Donnie Simpson (2016 apud SIMON, 2016), em entrevista à $N B C N e w s$, destacou a admiração e o respeito que o britânico tinha pela música e cultura negras.

Bowie, também, contratou negros para participar do processo criativo das suas músicas, para gravá-las em estúdio e, depois, para 
apresentá-las na turnê dos tempos de Young Americans. A participação das vozes negras não era abafada; de contrário, em Young Americans se ouve muito das vozes de apoio. $\mathrm{Na}$ banda da época do álbum, listam-se Diane Sumler, Robin Clark, Luther Vandross ${ }^{7}$, Ava Cherry ${ }^{8}$, Anthony Hinton, Carlos Alomar', Willie Weeks, Dennis Davis, Emir Ksasan, Ralph MacDonald e Larry Washington como músicos negros. Estes são 57,8\% do grupo, isto é, 11 de $19^{10}$ (GRIFFIN, 2021: não p.).

Embora se possa afirmar que Bowie definitivamente apropriou-se de elementos culturais negros - e que isso é polêmico -, vale dizer que o londrino muito valorizava os artistas afroamericanos. Ainda que, pelo mercado tipicamente racista, o holofote talvez pairasse sobre a alva cabeça alaranjada de Bowie, este apontava incessantemente para o talento da comunidade negra, apresentando ao público e apoiando fortemente nomes como Cherry, Vandross e Alomar. Embora se saiba que o resultado do chamado blue-eyed soul foi ofuscar talentos afrodescendentes e que por isso deve ser problematizado, Young Americans deve ser tida como uma peça que dignifica o trabalho negro, se se olha pelo escopo da intenção.

\footnotetext{
${ }^{7}$ Bowie tinha uma "relação especial" (SIMON, 2016: não p.) com Vandross, sobre quem tinha total crença de que "se tornaria uma estrela" num futuro próximo (SEYMOUR, 2004: 80, tradução minha).

${ }^{8}$ Bowie compôs quatro canções em 1973 e as entregou para Cherry, então sua namorada e backing vocal (CHERRY, 2016, não p.), e seu grupo, os Astronettes (DOGGETT, 2014: 257-259).

${ }^{9}$ Bowie teve uma longa parceria com Alomar, que durou de 1974 até 2003 (não consecutivamente).

${ }^{10}$ Aqui, não incluí no grupo dos 19 o próprio Bowie ou os produtores do álbum; mas inclui Lennon.
} 
Com isso tudo em mente é que busco afirmar que todo membro privilegiado da sociedade, seja por vias de gênero ou de raça, deve reconhecer a sua posição enquanto tal. Bowie soube observar a sociedade ao seu redor e enxergar a desvantagem sistêmica vivida pelos talentos negros na música, do que é evidência a crítica supracitada que fez à MTV; além de ter ele mesmo proposto incentivo a músicos afrodescendentes, notável por seus gestos. Contudo, deve-se entender que sua incursão pelos gêneros negros foi, de fato, problemática.

\section{Referências}

BOWIE, David. MTV News Interview. [Entrevista cedida a Mark Goodman]. MTV News, 2017. Disponível em: $<$ https://www.youtube.com/watch?v=L3i53rjh-PA>. Acesso em: 03 fev. 2021.

BOWIE, David; MASLIN, Harry; VISCONTI, Tony. Young Americans. Filadélfia; Nova Iorque: Sigma Sound; Record Plant, 1975. Disponível em: https://www.youtube.com/playlist?list=OLAK5uy_ntERq_t9Vo4qFWsDmr N_HbV5wP09AiFQo. Acesso em: 03 fev. 2021.

BOWIE GOLDEN YEARS. Young Americans. 2021. Disponível em: $<$ https://www.bowiegoldenyears.com/youngamericans.html $>$. Acesso em: 04 fev. 2021.

CHERRY, Ava. Ava Cherry, Former David Bowie Back-Up Singer \& Girlfriend, Reflects on Her 'First Love': Exclusive. Billboard, Nova Iorque, jan. 2016. Disponível em: $<$ https://www.billboard.com/articles/news/6842967/ava-cherry-david-bowi e-reflection>. Acesso em: 24 fev. 2021. 
BUCKLEY, David. Strange Fascination - David Bowie: The Definitive Story. Londres: Virgin Books, 2012.

DEMERS, Joanna. Teresa. Steal This Music: How intellectual property law affects musical creativity. Athens: University of Georgia Press, 2006.

DOGGETT, Peter. O homem que vendeu o mundo: David Bowie e os anos 70. Curitiba: Nossa Cultura, 2014.

SEYMOUR, Craig. Luther: the life and longing of Luther Vandross. Nova Iorque: HarperEntertainment, 2004.

SIMON, Mashaun. D. 'Plastic Soul': David Bowie's Legacy and Impact on Black Artists. NBC News, Nova Iorque, jan. 2016. Disponível em: $<$ https://www.nbcnews.com/news/nbcblk/plastic-soul-david-bowie-s-legacy -impact-black-artists-n494241>. Acesso em: 04 fev. 2021.

Recebido em: 05/02/2021 Aceito em: 24/02/2021 
Cadernos de Clio, Curitiba, v. 10, nº. 2, 2019

O conteúdo dos artigos e resenhas publicados nesta edição é de inteira responsabilidade de seus/suas autores/autoras, não representando a posição oficial dos/as editores/as e nem do conselho editorial da revista. 